\title{
An infrared 3D scanning device as a novel limb volume measurement tool in breast cancer patients
}

\author{
Bernadette N. White', Iris M. Lu², LeslieAnn S. Kao' ${ }^{1}$ J. Brandon Dixon², Michael J. Weiler ${ }^{3}$, Nathan D. Frank ${ }^{3}$,
} Jill Binkley ${ }^{4}$, Preeti Subhedar ${ }^{1}$, Joel Okoli ${ }^{5}$, Karen Buhariwalla ${ }^{6}$, Adriana Suarez-Ligon ${ }^{7}$ and Sheryl G. A. Gabram-Mendola ${ }^{1^{*}}$ (D)

\begin{abstract}
Background: Lymphedema is a common complication of breast cancer treatment that affects one in five breast cancer survivors, yet there is no reliable method to detect lymphedema in the subclinical range. The objective of this study was to determine the feasibility and reliability of using an infrared 3D scanning device (ISD) as a peri-operative limb volume measurement tool.

Methods: Fifteen patients were analyzed based on inclusion criteria. Peri-operative measurements were obtained using tape measure and an ISD. Volumes were calculated using a standard algorithm for tape measure and a custom algorithm for ISD measurements. Linear regression models were used to assess ISD and tape measurement volume and circumference correlation. One-way ANOVA was used to compare change in percent difference at set time points post-operatively (2-3 weeks, 4-6 weeks, and 7-12 weeks) for both ISD and tape measure. $t$ tests for unequal variances with the Bonferroni correction were performed among these groups.

Results: There is a positive linear correlation $\left(R^{2}=0.8518\right)$ between absolute volume measurements by the ISD and tape measure. Analyses over 2-10 weeks post-operatively showed that the ISD was able to detect volume changes in both the unaffected and the affected arm. Furthermore, the affected arm tended to have a greater increase in volume in the majority of patients, indicating these patients could be at risk for lymphedema.
\end{abstract}

Conclusions: Technology utilizing infrared 3D scanners can reliably measure limb volume pre- and post-treatment similarly to tape measure in a small sample of patients. Further research using 3D scanning technology with a longer follow up is warranted.

Keywords: Breast cancer rehabilitation, Lymphedema, Limb volume measurement, 3D technology

\section{Introduction}

Breast cancer is the most common cancer affecting women in the USA [1], and breast cancer-related lymphedema (BCRL) is the most common physical impairment affecting breast cancer survivors [2, 3]. Published data reports a wide range of $2-65 \%$ of breast cancer survivors suffering from lymphedema [3-6]. Lymphedema is a risk

\footnotetext{
* Correspondence: sgabram@emory.edu

${ }^{1}$ Emory University School of Medicine and Grady Memorial Hospital Avon Comprehensive Breast Center, Atlanta, GA, USA

Full list of author information is available at the end of the article
}

factor for other adverse events, including recurrent infection, functional impairments, decreased quality of life, and psychological distress [7-11]. Unfortunately, BCRL is frequently diagnosed after progressing to later stages and causing significant morbidity [12]. The pathology of lymphedema is partially to blame; patients begin to develop symptoms of arm heaviness, swelling, tightness, and achiness when arm volume increases 5-9.9\%, and clinicians cannot reliably diagnose lymphedema until $10-20 \%$ swelling [13-16]. A reliable limb volume measurement tool that detects swelling in the asymptomatic

\section{$\triangle B M C$}

(C) The Author(s). 2020 Open Access This article is licensed under a Creative Commons Attribution 4.0 International License, which permits use, sharing, adaptation, distribution and reproduction in any medium or format, as long as you give appropriate credit to the original author(s) and the source, provide a link to the Creative Commons licence, and indicate if changes were made. The images or other third party material in this article are included in the article's Creative Commons licence, unless indicated otherwise in a credit line to the material. If material is not included in the article's Creative Commons licence and your intended use is not permitted by statutory regulation or exceeds the permitted use, you will need to obtain permission directly from the copyright holder. To view a copy of this licence, visit http://creativecommons.org/licenses/by/4.0/ The Creative Commons Public Domain Dedication waiver (http://creativecommons.org/publicdomain/zero/1.0/) applies to the data made available in this article, unless otherwise stated in a credit line to the data. 
range of $3-5 \%$ is essential to identify BCRL early when it can be managed most effectively and progression can be reduced or avoided $[3,16]$.

The Prospective Surveillance Model (PSM) was proposed in 2012 [17] to provide a standardized method to screen survivors for physical impairments due to breast cancer. Major goals of the PSM included surveillance for common physical impairments, education to reduce risk, early identification of impairments, and introduction of rehabilitation and exercise interventions to treat lymphedema. Pre-operative assessment had previously been shown to improve the monitoring and detection of lymphedema [16], but no standardized method had been proposed until the PSM. A follow-up study implementing the PSM found that $15 \%$ of the patients who underwent breast cancer surgery developed lymphedema, and there was a need for individualized rehabilitation intervention in one-third of all patients who underwent breast cancer surgery [18]. The PSM was resource intensive, requiring frequent evaluation by physical therapists and demonstrated the need for reliable, affordable, easily reproducible, and user-friendly screening tools [18].

Commercial infrared sensors, such as the Xbox Kinect IR sensor (Microsoft, Inc, Redmond, USA), offer a method to fulfill these requirements [19]. Infrared scanning is quick, inexpensive, hygienic, has no radiation exposure, and is easily accessible to both clinics and patients; it has been utilized previously to generate volume measurements in pediatric patients with vascular malformations [20] and in patients with filarial lymphedema [21]. In these prior studies, measurement data was analyzed using proprietary software (LymphaTech, Atlanta, GA, USA) to produce a digital three-dimensional reconstruction of the patient's upper body from which a volume measurement of each limb was generated. This software system has been previously validated in the breast cancer population and found to generate reliable upper body measurements [22]. The Kinect IR sensor combined with this proprietary software has also previously been optimized by measuring more than 100 patients at risk for lymphedema at TurningPoint Breast Rehabilitation Center in Atlanta, Georgia [23]. Tape measurement was chosen in the current study as the comparison tool because it is the most-studied, most familiar and accessible to clinicians, and is reproducible if proper anatomical landmarks are established $[23,24]$.

The objectives of this study were (1) to determine how well the ISD volume calculations correlated with the tape measurements and (2) to determine the feasibility of implementing an ISD as a routine, easy-to-use clinical limb volume measurement tool. This study is the first known in the literature to apply the Kinect IR sensor as an ISD in a clinical setting for breast cancer patients, preand post-operatively at an urban, safety net hospital.

\section{Materials and methods}

This study was performed in the Avon Foundation Comprehensive Breast Center at Grady Memorial Hospital, a safety net hospital in Atlanta, Georgia. Enrollment started in June 2016 and concluded in June 2017. Chart review was performed prior to each breast surgical oncology clinic to identify patients who fit the inclusion and exclusion criteria for the study.

Inclusion criteria: stage 0-III breast cancer and patients receiving upfront surgery or returning for surgery after neoadjuvant therapy and before radiation therapy. Exclusion criteria included prior history of breast cancer, prior axillary surgery or radiation, and inability to stand for at least $5 \mathrm{~min}$. These criteria were established to capture patients receiving breast and axillary surgery and to exclude patients who already had any stage of lymphedema.

Following consent, the patient was led into a private room to complete the measurements. The examination room contained an examination table for performing tape measurements as well as the ISD, a Kinect IR sensor connected to a computer running proprietary software for limb volume measurement. Patients removed bracelets and watches and rolled up sleeves to the shoulder to ensure that the arm was not obstructed. Arms were first measured circumferentially using tape measurements every $4 \mathrm{~cm}$ from the ulnar styloid of the wrist to the axilla. Next, the patient stood approximately $6 \mathrm{ft}$. from the sensor with legs shoulder-width apart, head looking forward in neutral position, and the arms in proper positioning (Fig. 1) to obtain 4 measurements (front, back, right side, and left side), each side taking about $30 \mathrm{~s}$. Patient arm positioning had to fit two criteria: (1) at least $75^{\circ}$ from the trunk for anterior and posterior measurements, and 45 degrees for each side measurement, and (2) no more than $5^{\circ}$ of shoulder flexion anteriorly. As a guideline to assist the measuring researcher, a 3D reconstruction of the patient's body appeared on the connected computer, which turned from red to blue when the patient was within the appropriate parameters. The measuring researcher provided guidance to ensure that the patient was positioned within the defined parameters.

After obtaining the first pre-operative measurement, the patient was measured at subsequent post-operative visits at least 1 and up to 3 times. In addition to measurements, patient data was obtained and recorded in accordance with best clinical practices, including weight, height, body mass index (BMI), past medical and surgical history, and diagnosis and treatment plan. All data obtained was linked to a unique patient identifier code and stored for analysis with the measurements from the ISD and tape measurement data. 

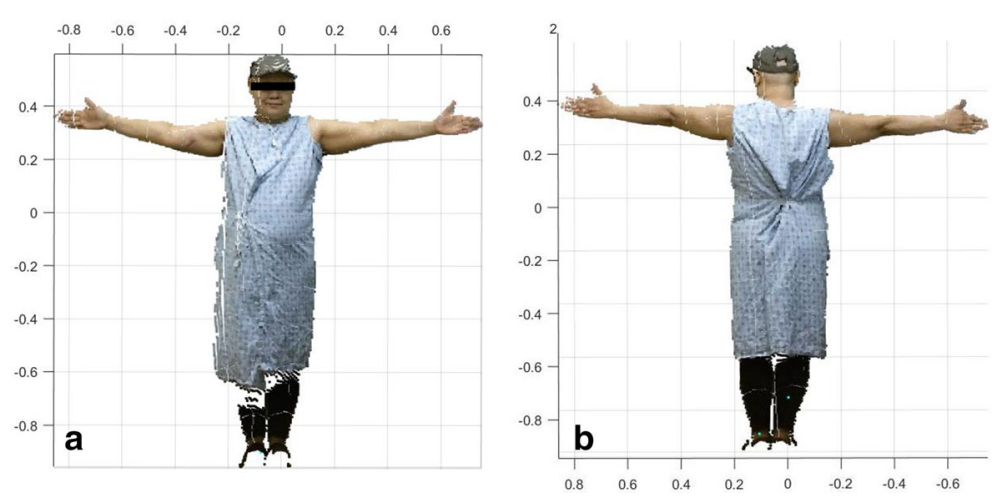

Fig. 1 a Point cloud 3D reconstruction-front. b Point cloud 3D reconstruction-back

Tape measurement volumes were calculated using the truncated cone method, which takes the circumferential measurements and outputs the volume. Volumes from the ISD were determined using a custom algorithm designed to calculate a volume measurement from the scans generated by the device (Fig. 1a, b). For both the tape measurements and the 3D measurements, the volume was calculated from wrist to axilla every $4 \mathrm{~cm}$, sparing the hand. Analysis by the GT team included a determination of the quality of the scans, from low to high quality, as well as the limb volume calculation. If scan quality was low, then a volume calculation could not be performed by the algorithm.

In order to differentiate between normal postoperative swelling, which can persist for several weeks following surgery, and BCRL, which typically presents months to years after treatment [25-28], percent differences in volumes between affected and unaffected arms were calculated with each 3D measurement. Percent difference was defined by convention as the difference between affected and unaffected limb volumes divided by the unaffected limb volume. A change greater than 5\% after the first 6 weeks post-operatively was considered concerning for possible subclinical lymphedema.

Linear regression was utilized to assess the ISD and tape measurement correlation and the operator variation. A Bland-Altman Plot was used to determine the agreement between the volumes gathered by the ISD and tape measure circumferences; the difference in measurement between the two modalities was plotted against the average. One-way ANOVA was used to compare change in percent difference at set time points post-operatively (2-3 weeks, 4-6 weeks, and 7-12 weeks) for both ISD and tape measure. $t$ tests for unequal variance were used to assess ISD measurement percent difference between these set post-operative time points. An alpha value was set to 0.05 , therefore, any $p$ value of $<0.05$ was considered significant.

\section{Results}

There were 106 eligible patients screened via chart review during the study period. Twenty-three patients were recruited and consented; 2 withdrew prior to completing the study. Seventeen patients had pre-operative scans from which volumes could be calculated, while 6 had scans that could not be calculated due to clothing covering portions of the arm. Fifteen patients had at least one post-operative scan, with the other 6 patients being lost to follow-up. Table 1 shows the demographics of the patients who completed the study. All patients had either SLNB or axillary dissection, with 6 out of the 15 participants undergoing axillary dissection.

Linear regression analysis of the 3D volume measurement and tape measurement volumes demonstrated a strong correlation $\left(R^{2}=0.8518\right)$, with the ISD tending to capture greater volumes than the tape measure technique (Fig. 2). A Bland-Altman plot indicating the degree of agreement between the two measurement techniques (Fig. 3) shows that larger arm volumes had less agreement between tape measure and the ISD.

Looking at the individual operator variation (Fig. 4), the correlation of the volume gathered by the ISD and the tape measure circumference measurements was strong for two operators and moderate for one $\left(R^{2}=\right.$ $0.8810,0.6403,0.9759)$. Variability from graph to graph was more pronounced for the tape measurements.

Percent differences in volume changes at weeks $2-3$, 4-6, and 7-12 were compared with one-way ANOVA for the ISD and tape measurement and were not found to be statistically significant. Additionally, $t$ tests for unequal variance for the 3D scanner using these same time points were not found to be statistically significant.

\section{Discussion}

From a clinical standpoint, this pilot study was successful in demonstrating a strong positive correlation with an $R^{2}$ of 0.8518 between limb volume calculations 
Table 1 Participant characteristics $(n=15)$

\begin{tabular}{|c|c|}
\hline Demographic characteristics & Count (\%) \\
\hline \multicolumn{2}{|l|}{ Age } \\
\hline$<40$ & $2(13)$ \\
\hline $41-65$ & $9(60)$ \\
\hline$>65$ & $4(27)$ \\
\hline \multicolumn{2}{|l|}{ Race } \\
\hline White & $1(6)$ \\
\hline African American & $14(93)$ \\
\hline \multicolumn{2}{|l|}{ Comorbidities } \\
\hline Hypertension & $9(60)$ \\
\hline Diabetes mellitus & $4(27)$ \\
\hline Tobacco use & $2(13)$ \\
\hline \multicolumn{2}{|l|}{ Body mass index $\left(\mathrm{kg} / \mathrm{m}^{2}\right)$} \\
\hline < 18.5 (underweight) & 0 \\
\hline 18.5-24.9 (normal) & $4(27)$ \\
\hline 25-29.9 (overweight) & $5(33)$ \\
\hline > 30.0 (obese) & $6(40)$ \\
\hline \multicolumn{2}{|l|}{ Breast cancer history } \\
\hline \multicolumn{2}{|l|}{ Stage } \\
\hline 0 & $1(6)$ \\
\hline 1 & $4(27)$ \\
\hline 2 & $7(47)$ \\
\hline 3 & $3(20)$ \\
\hline \multicolumn{2}{|l|}{ Breast cancer type } \\
\hline DCIS & $1(7)$ \\
\hline Invasive ductal & $13(87)$ \\
\hline Invasive lobular & $1(7)$ \\
\hline \multicolumn{2}{|l|}{ Breast cancer treatment } \\
\hline Neoadjuvant chemotherapy & $9(60)$ \\
\hline \multicolumn{2}{|l|}{ Surgery } \\
\hline Partial mastectomy with SLNB ${ }^{a}$ & $3(20)$ \\
\hline Simple unilateral mastectomy with SLNB & $5(33)$ \\
\hline Modified radical mastectomy & $4(27)$ \\
\hline Bilateral mastectomy & $3(20)$ \\
\hline \multicolumn{2}{|l|}{ Lymph nodes removed during surgery } \\
\hline $1-5$ & $8(53)$ \\
\hline $6-10$ & $1(7)$ \\
\hline Axillary dissection & $6(40)$ \\
\hline
\end{tabular}

${ }^{\mathrm{a} S N L B}$ sentinel lymph node biopsy

obtained with a well-known and studied modality, circumferential tape measurements, and a novel infrared 3D scanning technology. The study also showed that symptomatic volume changes could be detected by the device, as one patient who was already undergoing treatment for lymphedema was found by the 3D scanner to have an increase in limb volume of about $15 \%$.

\section{Volume Comparison}

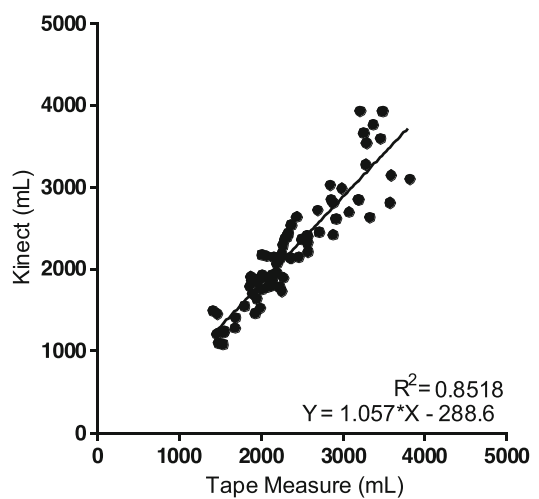

Fig. 2 Linear regression curve for volume as measured by tape measurement and ISD

The secondary goal of this study was to test how feasible the ISD would be as a routine screening instrument in the breast cancer clinic. We found that this device was easy to implement in the clinical setting and has distinct advantages compared to the other modalities currently in use. The infrared sensor that forms the backbone of this ISD uses similar technology to the Perometer, which is a highly sensitive optoelectrical scanner, and has been found to have a standard error of measurement (SEM) of $2.1 \%$ in one systematic review [29]. In comparison, in that same study, the SEM for tape measure was found to be $2.8 \%$, and the SEM of water volumetry was $0.7 \%$. Another method of evaluating for lymphedema is bioimpedance spectroscopy (BIS), which uses a low-frequency electrical current to detect the amount of fluid in the area of interest.

While studies have shown a lower incidence in lymphedema severity amongst breast cancer patients after treatment when undergoing early surveillance with BIS compared to a traditional referral model of care [30], there are no reports directly comparing the efficacy of early surveillance models leveraging BIS versus using limb volume changes. BIS has only been found to have modest correlation to Perometer, with one study finding $R=0.60$ [31]. In addition, there have been reports that BIS has a false-negative rate of over $30 \%$ when compared to directly imaging lymphatic vessels using indocyanine green (ICG) lymphography [32]. There are also several emerging modalities that allow for the direct imaging of lymphatic vessels to detect abnormalities [33, 34]. These approaches will likely face challenges associated with widespread clinical adoption due to the need for expensive instrumentation or the injection of contrast agents. 


\section{Bland-Altman Plot}

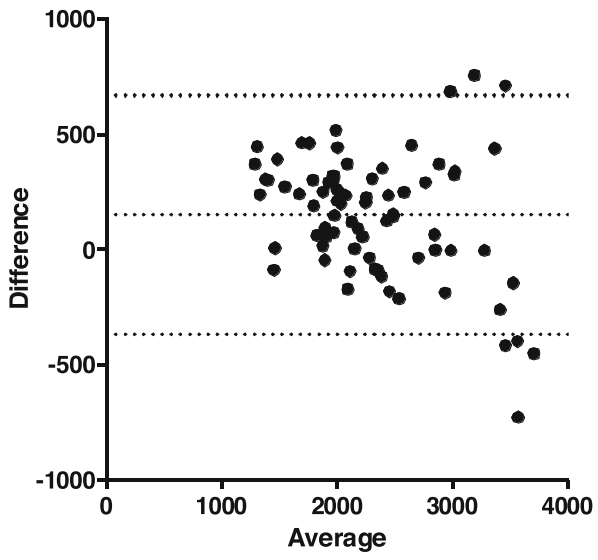

Fig. 3 Bland-Altman plot of agreement between volumes gathered by ISD versus tape measure

An ISD offers similar accuracy to both tape measure and perometry, with our study finding a strong positive correlation to tape measure, and previous studies with larger cohorts of patients comparing volumes measured by this ISD and a Perometer, a precise tool to measure limb volumes, have found good correlation between the two $\left(R^{2}=0.8799\right)$ [35]. Importantly, the ISD costs a fraction of the price of Perometer (approximately $\$ 20,000$ ) or of BIS (approximately $\$ 10,000$ ), with the sensor averaging $\$ 400$, while not sacrificing accuracy in detection of volume changes.

This study identified that the ISD accurately measures patients with body types ranging from normal weight to obese. The reasons for scans failing were improper body positioning and clothing that covered up a portion of the arms, not the circumference or volume of the patient's arms. However, an important limitation of the device noted in this study is that there was more variability between the infrared measurements of larger limb volumes. In the future, problems with positioning may be resolved by utilizing hand supports to optimize arm position and minimize motion since the hands are not included as part of the arm volume calculation. This study also underscores the need for proper training of the staff measuring patients using these 3D scanners. Inter-operator variability was strong for two researchers and moderate for a third; adequate understanding of the parameters of the device will improve scan acquisitions and measurements and decrease variability between operators.

Other limitations of this study include the following: (1) it was conducted at a single institution, safety-net hospital, with a primarily Black population and so the results may not be representative of the general population; (2) it is a small sample size, making it difficult to draw conclusions about this ISD's overall ability to measure volumes in a large cohort of patients [35]; and (3) the short duration of the study. Although volume changes were detected in this study, lymphedema develops in most breast cancer survivors over the course of years, and so longer follow-up with additional measurements is needed to determine if this ISD detects persistent and increasing volume changes. Finally, there is a lack of post-operative data for every patient enrolled in the study due to patient factors, time constraints of the study, and the limitations in the device discussed above. Thus, it was not possible to perform rigorous statistical analyses to test the ability of the ISD to detect volume changes over time as compared to tape measurement. However, since this was a pilot study intended to test feasibility, at this early stage this is an acceptable limitation.

Despite the study limitations, this feasibility study for the use of novel 3D scanning technology is an important step in lymphedema research. The patient data collected in conjunction with this study will help better identify

\section{Operator Variation}
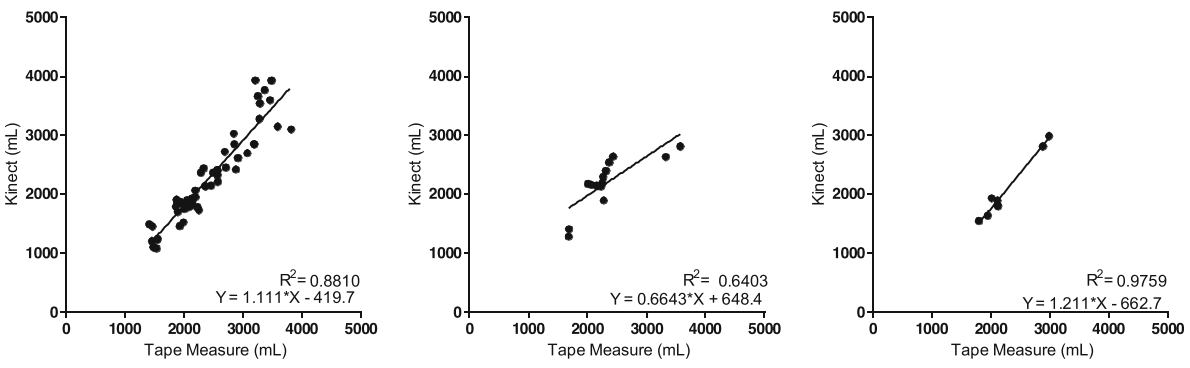

Fig. 4 Inter-operator variability. Each graph represents an individual operator who took tape measurements and ISD scans 
patients at risk for lymphedema. Additionally, knowledge gathered in this study will be important for studying the pathophysiology and underlying causes of lymphedema and tissue swelling of all causes. The current study is an important step in assessing all types of patients in a quick and non-invasive manner.

\section{Conclusion and clinical practice points}

This study was the first to demonstrate that a novel infrared 3D scanning technology, the Kinect IR sensor combined with volume calculation software, accurately measures limb volumes in breast cancer patients with comparable results to tape measure circumferential measurements. Further research using 3D scanning technology with a longer follow up is warranted.

- Infrared 3D scanning devices can measure limb volume, are easy to use, and are time efficient.

- Infrared 3D scanning device measurements and tape measure circumference measurements of limb volume in breast cancer surgical patients are strongly correlated.

- This pilot study supports the need for further research on the use of these infrared 3D scanning devices to assess for lymphedema in peri-operative breast cancer patients.

\section{Acknowledgements}

We acknowledge the staff of the Avon Foundation Breast Center at Grady Hospital and Stephanie Kirkpatrick for assistance with learning the technique of tape measure limb volume measurement.

\section{Authors' contributions}

Data collection: LK, KB, ASL. Data analysis and interpretation: IL, LK, JBD, MW, and NF. Drafting and editing manuscript: BW, LK, JB, PS, JO, SGM. Approval final version and consent to submit: All authors.

\section{Funding}

This study was funded with a grant from the Avon Foundation and the Avon Breast Cancer Crusade.

\section{Availability of data and materials}

The datasets used and/or analyzed during the current study are available from the corresponding author on reasonable request.

\section{Ethics approval and consent to participate}

Study approval was obtained from the Institutional Review Boards of both Emory University (IRB00084299) and Georgia Institute of Technology (H16120). Patients provided informed written consent for enrollment and agreed to any use of their data for publication.

\section{Consent for publication}

Part of the consent form included a statement about "sharing data with other researchers." Patients also understood and signed in the consent document that "the study results may be used to help others in the future and may find a better way to detect lymphedema at an earlier stage than our current methods currently do." Finally, the consent document (signed by the patient) stated that "the patient's name and other identifying information will not appear when we present or publish the study results."

\section{Competing interests}

Three of the authors on this paper have pertinent financial interests to disclose. J. Brandon Dixon and Michael J. Weiler invented the LymphaTech technology used in this study and they are eligible to receive royalties under the license agreement with Lymphatech. Dr. Dixon, Dr. Weiler, and Mr. Nathan D. Frank own equity in LymphaTech and Dr. Dixon serves as a scientific advisor to the company. The remaining authors (BW, IL, LK, JB, PS, JO, KB, ASL, and SGM) declare that they have no competing interests.

\section{Author details}

${ }^{1}$ Emory University School of Medicine and Grady Memorial Hospital Avon Comprehensive Breast Center, Atlanta, GA, USA. ${ }^{2}$ Georgia Institute of Technology, Atlanta, GA, USA. ${ }^{3}$ LymphaTech Inc., Atlanta, GA, USA.

${ }^{4}$ TurningPoint Breast Cancer Rehabilitation, Atlanta, GA, USA. ${ }^{5}$ Morehouse School of Medicine, Atlanta, GA, USA. ${ }^{6}$ Cherokee Breast Center Northside Hospital, Canton, USA. ${ }^{7}$ Rutgers New Jersey Medical School, Newark, NJ, USA.

Received: 20 July 2020 Accepted: 2 October 2020

Published online: 27 October 2020

\section{References}

1. Surveillance, Epidemiology, and End Results (SEER) Program, Research Data (1973-2013), National Cancer Institute, DCCPS, Surveillance Research Program, Surveillance Systems Branch. Cancer Stat Facts: Female Breast Cancer. Available from URL: https://seer.cancer.gov/statfacts/html/breast. html [accessed 9/29/2020)

2. Cheville AL, Troxel AB, Basford JR, Kornblith AB. Prevalence and treatment patterns of physical impairments in patients with metastatic breast cancer. J Clin Oncol. 2008:26:2621-9.

3. Shah C, Vicini FA. Breast cancer-related arm lymphedema: incidence rates, diagnostic techniques, optimal management and risk reduction strategies. Int J Radiat Oncol Biol Phys. 2011;81:907-14.

4. DiSipio T, Rye $S$, Newman B, Hayes $S$. Incidence of unilateral arm lymphoedema after breast cancer: a systematic review and meta-analysis. Lancet Oncol. 2013;14:500-15.

5. Hayes SC, Janda M, Cornish BH, Battistutta D, Newman B. Lymphedema secondary to breast cancer: how choice of measure influences diagnosis, prevalence, and identifiable risk factors. Lymphology. 2008;41:18-28. https:// journals.uair.arizona.edu/index.php/lymph/article/view/17060. Accessed 29 Sept 2020.

6. Petrek JA, Senie RT, Peters M, Rosen PP. Lymphedema in a cohort of breast carcinoma survivors 20 years after diagnosis. Cancer. 2001;92:1368-77.

7. Penha TR, Botter B, Heuts EM, Voogd AC, von Meyenfeldt MF, van der Hulst RR. Quality of life in patients with breast cancer-related lymphedema and reconstructive breast surgery. J Reconstr Microsurg. 2016;32(6):484-90.

8. Hull MM. Lymphedema in women treated for breast cancer. Semin Oncol Nurs. 2000;16:226-37.

9. Fu MR, Ridner SH, Hu SH, Stewart BR, Cormier JN, Armer JM. Psychosocial impact of lymphedema: a systematic review of literature from 2004-2011. Psychooncology. 2013;22:1466-84.

10. Passik SD, McDonald MV. Psychosocial aspects of upper extremity lymphedema in women treated for breast carcinoma. Cancer. 1998;83: 2817-20

11. Shih Y-CT XY, Cormier JN, et al. Incidence, treatment costs, and complications of lymphedema after breast cancer among women of working age: a 2-year follow-up study. J Clin Oncol. 2009;27:2007-14.

12. Armer JM. The problem of post-breast cancer lymphedema: impact and measurement issues. Cancer Investig. 2005;23:76-83.

13. Cormier JN, Xing Y, Zaniletti I, Askew RL, Stewart BR, Armer JM. Minimal limb volume change has a significant impact on breast cancer survivors. Lymphology. 2009;42:161-75 https://journals.uair.arizona.edu/index.php/ lymph/article/view/17073.

14. Armer JM, Ballman KV, McCall L, et al. Lymphedema symptoms and limb measurement changes in breast cancer survivors treated with neoadjuvant chemotherapy and axillary dissection: results of American College of Surgeons oncology group (ACOSOG) Z1071 (Alliance) substudy. Support Care Cancer. 2019;27:495-503.

15. Armer JM, Hulett JM, Bernas M, Ostby P, Stewart BR, Cormier JN. Best practice guidelines in assessment, risk reduction, management, and surveillance for post-breast cancer lymphedema. Curr Breast Cancer Rep. 2013;5:134-44.

16. Stout Gergich NL, Pfalzer LA, McGarvey C, Springer B, Gerber LH, Soballe P. Preoperative assessment enables the early diagnosis and successful treatment of lymphedema. Cancer. 2008;112:2809-19. 
17. Stout NL, Binkley JM, Schmitz KH, et al. A prospective surveillance model for rehabilitation for women with breast cancer. Cancer. 2012;118:2191-200

18. Lai L, Binkley J, Jones $V$, et al. Implementing the prospective surveillance model (psm) of rehabilitation for breast cancer patients with 1-year postoperative follow-up, a prospective, observational study. Ann Surg Oncol. 2016;23:3379-84.

19. Moreira R, Magalhães A, Oliveira HP. A kinect-based system to assess lymphedema impairments in breast cancer patients. Cham: Springer International Publishing; 2015. p. 228-36.

20. Speir EJ, Matthew Hawkins C, Weiler MJ, et al. Volumetric assessment of pediatric vascular malformations using a rapid, hand-held three-dimensional imaging system. J Digit Imaging. 2019;32:260-8.

21. Yahathugoda C, Weiler MJ, Rao R, et al. Use of a novel portable threedimensional imaging system to measure limb volume and circumference in patients with filarial lymphedema. Am J Trop Med Hyg. 2017:97:1836-42

22. Binkley JM, Weiler MJ, Frank N, Bober L, Dixon JB, Stratford PW. Reliability and convergent validity of the lymphatech system to assess arm volume in patients during and after treatment for breast cancer. Phys Ther. 2020; 100(3):457-67.

23. Mayrovitz HN. Limb volume estimates based on limb elliptical vs. circular cross section models. Lymphology. 2003;36:140-3. https://journals.uair. arizona.edu/index.php/lymph/article/view/17243. Accessed 29 Sept 2020.

24. Taylor R, Jayasinghe UW, Koelmeyer L, Ung O, Boyages J. Reliability and validity of arm volume measurements for assessment of lymphedema physical therapy. Phys Ther. 2006;86:205-14.

25. Warren AG, Brorson H, Borud LJ, Slavin SA. Lymphedema : a comprehensive review. Ann Plast Surg. 2007;59:464-72.

26. Tandra P, Kallam A, Krishnamurthy J. Identification and management of lymphedema in patients with breast cancer. Journal of Oncology Practice. 2019;15:255-62.

27. Mortimer PS. The pathophysiology of lymphedema. Cancer. 1998;83:2798-802.

28. Armer JM, Stewart BR. Post-breast cancer lymphedema: incidence increases from 12 to 30 to 60 months. Lymphology. 2010;43:118-27 https://journals. uair.arizona.edu/index.php/lymph/article/view/17011.

29. Hidding JT, Viehoff PB, Beurskens $\mathrm{CH}$, et al. Measurement properties of insturments for measuring of lymphedema: systematic review. Phys Ther. 2016:96(12):1965-81.

30. Ridner SH, Dietrich MS, Cowher MS, et al. A randomized trial evaluating bioimpedance spectroscopy versus tape measurment for the prevention of lymphedema following treatment for breast cancer: interim analysis. Ann Surg Oncol. 2019;26(10):3250-9.

31. Bundred NJ, Stockton C, Keeley V, et al. Comparison of multi-frequency bioimpedance with perometry for the early detection and intervention of lymphedema after axillary node clearance for breast cancer. Breast Cancer Res Treat. 2015;151(1):121-9.

32. Qin ES, Bowen MJ, Chen WF. Diagnostic accuracy of bioimpedance spectroscopy in patients with lymphedema: a retrospective cohort analysis. J Plast Reconstr Aesthet Surg. 2018;71(7):1041-50.

33. Polomska AK, Proulx ST: Imaging technology of the lymphatic system. Advanced Drug Delivery Reviews. On line Sept $3^{\text {rd }}, 2020$.

34. Dixon JB, Weiler MJ. Bridging the divide between pathogenesis and detection in lymphedema. Semin Cell Dev Biol. 2015;38:75-82.

35. Lu IM, Dixon JB. Assessment of upper extremity swelling among breast cancer survivors with a commercial infrared sensor. Lymphatic Res Biology. 2019

\section{Publisher's Note}

Springer Nature remains neutral with regard to jurisdictional claims in published maps and institutional affiliations.

Ready to submit your research? Choose BMC and benefit from:

- fast, convenient online submission

- thorough peer review by experienced researchers in your field

- rapid publication on acceptance

- support for research data, including large and complex data types

- gold Open Access which fosters wider collaboration and increased citations

- maximum visibility for your research: over $100 \mathrm{M}$ website views per year

At $\mathrm{BMC}$, research is always in progress.

Learn more biomedcentral.com/submissions 